\title{
UNEXPECTED EVENTS DURING SURVEY DESIGN AND TRUST IN THE POLICE: A SYSTEMATIC REVIEW
}

A PREPRINT

\author{
Christof Nägel \\ Department of Sociology \\ Utrecht University \\ Utrecht, The Netherlands \\ c.r.e.nagel@uu.nl
}

\author{
Amy E. Nivette \\ Department of Sociology \\ Utrecht University \\ Utrecht, The Netherlands \\ a.e.nivette@uu.nl
}

April 4, 2022

\begin{abstract}
Objectives: The current review has two aims: 1) to synthesize the impact of unexpected events on trust in police across different contexts and types of events, and 2) to evaluate the methodological characteristics of each study with attention to the assumptions for causal inference.

Methods: We conducted a pre-registered narrative systematic review on 12 independent studies.

Results: Studies closely adhering to causal inference assumption checks (i.e. excludability and ignorability) find significant changes in trust in police following incidents of police (non) violence and protest. Still, excludability is assessed and addressed less rigorously than ignorability in the included studies.

Conclusion: Regarding the procedural justice framework, this provides some causal evidence that vicarious (positive and negative) experiences can shape short-term assessments of public trust in police. We furthermore highlight issues related to design and power, statistical conclusion validity, and the evaluation of assumptions to detect threats to internal validity.
\end{abstract}

Keywords causal inference $\cdot$ trust in police $\cdot$ unexpected event $\cdot$ ignorability $\cdot$ excludability

Accepted for publication in Journal of Experimental Criminology

This research was supported by the Netherlands Organisation for Scientific Research (NWO) Talent Grant [grant number: VI.Vidi.191.135]. 
A PREPRINT - April 4, 2022

\section{Introduction}

A great deal of research on perceptions of police tends to be based on cross-sectional correlational studies (Nagin \& Telep, 2017; Walters \& Bolger, 2019). While there are a growing number of Randomized Controlled Trials (RCTs), often considered the "Gold Standard" of social scientific research, these studies tend to lack external validity or "policy transfer" (Sampson, 2010). Natural experiments, and the use of instrumental variables in general, can offer the opportunity to address some of the limitations of cross-sectional and RCT studies (Angrist, 2006). Aside from increasing external validity of research findings (Meyer, 1995), natural experiments might help to more adequately address issues related to simultaneity, measurement error, and selection bias (Bushway \& Apel, 2010).Furthermore, some obvious ethical problems arise when researching sensitive topics such as the effects of insecurity, political violence, and police abuse on public perceptions of policing in a real-life experimental setting. For example, regarding procedural justice theory, there are clear limits to the manipulation of the displayed (un-)fairness in personal interactions with police officers in survey experiments or even a RCT. In a natural experiment, however, actual events can be used as quasi-experimental stimuli for vicarious experiences, which alleviates some of the ethical problems mentioned above and might even increase internal validity given that the causal inference assumptions are adequately addressed.

Muñoz et al. (2020) have described a special type of natural experiment that may prove particularly important for studying high profile events and their implications for police legitimacy and trust in the police: the Unexpected Event During Survey Design (UESD). This identification strategy relies on the timing of the interview as the instrumental variable, as it affects the outcome of interest through the occurrence of an unexpected event. This research design has gained prominence through studies that examine the effect of terrorist attacks on attitudes toward ethnic minorities (Bove et al., 2021; Legewie, 2013; Nussio et al., 2019).

Within criminology, interest has grown in assessing the impact of unexpected events on public attitudes towards the police (Kochel, 2019; Kochel \& Skogan, 2021; Nägel \& Lutter, 2021; Reny \& Newman, 2021; Thomassen et al., 2014). These events can be considered "vicarious experiences" (Weitzer, 2002), depending on the media salience, police reactions, and societal context (Cheng, 2021; O'Brien et al., 2020), rendering them appropriate quasi-experimental "manipulations" to study the dynamics of public perceptions of police within the UESD setup. For example, following the death of Michael Brown in Ferguson, Missouri, questions arose as to what extent this incident of police violence mobilized and changed attitudes towards the police (Kochel, 2019). Previous research has so far assessed a wide range of events, including incidents involving police actions (e.g. violence, misconduct, policing peaceful protests, Nägel \& Lutter, 2021; Oglesby-Neal et al., 2019; Reny \& Newman, 2021; White et al., 2018; Zoorob, 2020) as well as large-scale global or societal events (e.g. terrorist attacks, public health crises, Dinesen \& Jaeger, 2013; Fenn \& Brunton-Smith, 2021; LaFree \& Adamczyk, 2017; Sibley et al., 2020). It is important to understand how these events influence trust in police since trust has been associated with cooperation and compliance (Tyler, 2006; Tyler \& Huo, 2002), criminal behavior (Dawson, 2018; Eisner \& Nivette, 2013), trust in the state itself (Jeong \& Han, 2020), and social polarization in general (Jefferis et al., 1997; Kochel, 2019; Nägel \& Lutter, 2021; Reny \& Newman, 2021). Accordingly, there is a strong argument that "[s]tudies that are able to capture the dynamic of cleavages and their consequences for police legitimacy in such instances are important" (Roché \& Roux, 2017, p. 16). However, an appropriate summary of research findings in this strand of research is still lacking, and more importantly, there is little guidance for researchers striving to apply this particular design within the field of criminology.

Although UESD can be beneficial for assessing the impact of high-profile incidents on public opinion, there are important practical and methodological conditions that must be met in order to reliably estimate causal effects (Muñoz et al., 2020). One practical requirement is that the timing of unexpected police events overlaps with survey fieldwork that includes questions about perceptions of the police. Methodologically, the 
estimation of causal effects depends on two important assumptions: the excludability assumption (sometimes also referred to as the temporal stability assumption) simply implies that without the treatment event, there would be no effect on the outcome. Testing for this assumption therefore includes the checking of collateral events and unrelated time trends. The ignorability assumption states that the chance of being assigned to either pre - or post - event group should be as-good-as-random.

The current review has two aims:

1. to synthesize the impact of unexpected events on trust in police across different contexts and types of events, and

2. to evaluate the methodological characteristics of each study with attention to the assumptions for causal inference.

As a result, we expect to contribute to the understanding of the impact of vicarious experiences on trust in police among the general public, as well as a critical overview of the use of natural experiments in research on trust in police.

In addition, we will provide a thorough but accessible guide for implementing the UESD approach in criminological research, with an application to policing research. Our focus will be on clear identification of main effects. Therefore, we will only address heterogeneous effects briefly and focus on testing the pertinent causal inference assumptions. Notable combinations of the UESD with the classical Regression Discontinuity Design (RDD) or the Difference-in-Differences (DiD) design will be addressed as well as statistical power issues and the correct calculation of standard errors. Accordingly, our summary of the UESD approach in this specific context will provide best-practice recommendations for its application in these contexts and beyond.

\subsection{Unexpected events and perceptions of police}

Research on high-profile events, such as police violence or terrorist attacks, tends to rely on two main theoretical frameworks to explain public response to these events. The first framework is concerned with explaining how perceptions might change in response to specific police actions during incidents. Based on procedural justice theory, the public formulates their judgements based on how the police treated those involved in the incident (Tyler, 2006; Tyler \& Jackson, 2014). When the police treat people with fairness, respect, and neutrality, the public is expected to revise their views of the police upwards, leading to higher trust and legitimacy (Hough et al., 2010; Sunshine \& Tyler, 2003). Incidents of police violence can be seen to violate these principles of procedural justice, resulting in more negative perceptions of police (Curtice, 2021; Nägel \& Lutter, 2021; Perry et al., 2017; White et al., 2018). Research shows that following high-profile incidents of police violence, public reactions can be polarized, whereby members of affected minority groups may react more strongly than majority groups (Kochel, 2019; Nägel \& Lutter, 2021; Reny \& Newman, 2021). This also relates to distributive justice theory since police violence against ethnic minorities can trigger the notion that misconduct is unevenly distributed among ethnic groups (Weitzer, 2019).

The second framework aims to explain changes in attitudes following major crises, such as terrorist attacks or public health emergencies. Based on the notion that these types of events can be characterized as an "external" threat to societal institutions and daily life, the public is expected to "rally around the flag" to support threatened institutions, including the police (Perrin \& Smolek, 2009; Sibley et al., 2020; Van Hauwaert \& Huber, 2020). Collective threats that lead to uncertainty and angst are expected to "activate" in-group solidarity and diffuse support for political and criminal justice institutions (Porat et al., 2019; Schraff, 2020; Sibley et al., 2020). From this perspective, rally effects are considered emotional reactions to collective threats as opposed to post-hoc evaluations of institutional response to crises (Schraff, 2020). For example, "rally effects" were observed following the onset of the COVID-19 pandemic and subsequent nationwide lockdowns 
in March 2020 (Bol et al., 2021; Esaiasson et al., 2021; Kritzinger et al., 2021; Schraff, 2020). The COVID-19 pandemic has been described as a "foreign" or external shock "inflicting sudden and unprecedented hardship on societies at large" (Kritzinger et al., 2021, p. 1206).

Given that events occur unexpectedly during survey fieldwork, the temporal window before and after treatment can vary substantially across countries. While some studies have found lasting "rally effects" on support for political institutions (e.g. several weeks to over a year, Gaines, 2002; Hetherington \& Nelson, 2003), changes in trust in police following police actions or societal crises tend to be short-lived, sometimes lasting only days or weeks following the event (Nägel \& Lutter, 2021; Reny \& Newman, 2021).

\subsection{Issues with causal inference: ignorability and excludability}

Researchers have called attention to the lack of causal evidence to support the connection between police actions, public opinion, and behavior (Graziano, 2019; Nagin \& Telep, 2020). As a quasi-experiment, the UESD allows the dynamics of public attitudes to be explored in a "natural setting" without sacrificing the unique advantages of random allocation that would be provided by an RCT. However, the natural setting also carries threats to validity, as the influence of unobserved variables, unknown seasonal time trends, and collateral events often cannot be completely ruled out or controlled for. This naturally places enormous demands on researchers to examine the relevant assumptions as rigorously as possible in order to utilize the promises of this identification strategy without falling into the many potential pitfalls. These important assumptions are referred to in contemporary research as the excludability assumption and the ignorability assumption (Muñoz et al., 2020).

Exludability, also known as the temporal stability assumption (Legewie, 2013), implies that the timing, as an instrument for the focal event's effect on the outcome, affects the outcome through no other channel than the event itself. This is conceptually similar to the exclusion restriction in instrumental variable estimation, since the exclusion restriction states that, conditional on covariates, the instrument (survey timing) cannot be correlated with the error term (e.g., other events) in the explanatory equation (Labrecque \& Swanson, 2018; Stock \& Watson, 2007). There are at least four situations in which this assumption might be violated: collateral events, simultaneous events, unrelated time trends, and endogenous timing of the event (Muñoz et al., 2020). Collateral events are happenings that are triggered by the actual event in question. Unrelated time-trends refer to much observed seasonal opinion patterns like mood changes (Rosenthal \& Wehr, 1987), which could lead to biased treatment effects when these variables also correlate with the outcome. Finally, endogenous timing of the event refers to a situation in which the focal event is triggered by actors who can strategically choose when to disclose information on said event. For example, when partisan media postpones printing articles on corruption scandals until close to an election to maximize potential damage, it becomes more difficult to isolate the event's effect since public opinion might be driven instead by the election (Ares \& Hernández, 2017). Strategies to assess these potential violations include placebo treatments, inspection of pre-existing time-trends, falsification tests on other outcomes or other surveys/observations, as well as a detailed qualitative description of the event to give an overview of how the event rose in salience (Mellon, 2014; Muñoz et al., 2020).

The ignorability assumption addresses whether the quasi-experimental setting can be considered as truly experimental, or, in other words, whether the chance of being assigned to either the control or the treatment group is as-good-as-random (Bor et al., 2014; Gangl, 2010; Legewie, 2013; Muñoz et al., 2020). Regarding this causal inference assumption, the reachability and regional sampling biases are concerned with potential systematic differences in survey participation (Legewie, 2013). Muñoz et al. (2020) argue that fieldwork organization and attrition are also potential threats to the violation of this assumption. These violations result in imbalances between the pre- and post-event groups. The most straightforward test is a simple mean comparison of relevant covariates (i.e., age, education, sex, income) on the binary event indicator. While 
significant differences violate the ignorability assumption, there are strategies to address these violations and check robustness through covariate adjustment, matching procedures, and the use of multiple bandwidths. Non-response patterns can be analyzed to assess whether fieldwork determinants or attrition is a danger to the validity of the design. Additionally, a qualitative description of the event can provide insights into the extent to which the event was unexpected (Muñoz et al., 2020). If the event was foreseeable, participants may have changed their opinions beforehand and the timing of the interview becomes less reliable as an instrument for treatment assignment 1

\section{Methods}

The purpose of this systematic review is to provide an overview of research that has examined the impact of unexpected events on trust in the police. The protocol for this systematic review was pre-registered on OSF in August 2021 https://osf.io/4mj89/.

\subsection{Search strategy and criteria}

\subsubsection{Types of studies}

This review focuses on studies that quantitatively assessed the impact of unexpected events on public perceptions of police. The events included in the review should have taken place during periods of ongoing survey fieldwork. This excludes studies that examined planned or reasonably foreseeable events such as the implementation of policies and more straightforward before and after designs (e.g. Kang, 2021; Vidales et al., 2009).

\subsubsection{Types of outcome measures}

The outcome variable of interest is any attitudinal measure of general police performance, including confidence, trust, or overall satisfaction. This excludes perceptions measures of officer-reported perceptions of public approval (Turchan, 2021), positive or negative sentiments scraped from Twitter (Oglesby-Neal et al., 2019), proximal behavioral responses such as cooperation with the police (LaFree \& Adamczyk, 2017), and emergency or service calls to the police (Zoorob, 2020).

\subsubsection{Additional inclusion criteria}

As the focus is on causal inference using unexpected events, we did not restrict the type of event or the geographical origin of the data. The timeframe covered spans from 1970 to the date of the search (August 2021). The language of the study is restricted to English.

\subsubsection{Search methods}

The search strategy proceeded in three stages:

1. An initial search was performed using single database (Web of Science) in order to refine the search strings. Titles and abstracts were reviewed in order to add or adjust keywords. The initial search

\footnotetext{
${ }^{1}$ Muñoz et al. (2020) also include heterogenous treatment effects and post treatment bias in their list of possible violations. Post treatment bias refers to a situation in which both the outcome as well as a potential moderator will be affected by the event. For example, a Jihadist terror attack that could theoretically affect attitudes toward refugees. The effect might be stronger for people identifying with right-wing parties, but the event could also influence identification with those parties. This creates a "bad control" problem from a causal inference perspective (Angrist \& Pischke, 2009) since the group before the event is not comparable anymore to the group after the event due to a potential ideological shift among participants. Since we do not assess moderation effects, we do not specifically assess this violation.
} 
revealed that the use of methodological search terms such as "natural experiment" or "difference-indifferences" were too restrictive, and so they were omitted from the primary search.

2. The primary search was then conducted using the following keywords: "misconduct" OR "highprofile" OR "terrorist attack" OR "scandal" OR "corruption" OR "incidents," police OR policing (alternatively, "trust in institutions" OR "trust in government"), and attitudes OR perceptions OR trust OR confidence.

3. Google Scholar was used to supplement the search of primary databases and to scan the citation lists to identify any studies that may have been missed.

\subsubsection{Electronic databases}

The primary search was conducted using three primary scholarly databases: Scopus, Web of Science, and EBSCO Host. Google Scholar was used to scan for pre-prints or other grey literature that may not be published in an academic journal or formal publication. In addition, the reference lists from the selected studies were also searched for any additional studies that meet the search criteria.

\subsection{Data collection and analysis}

\subsubsection{Study selection}

The process to determine relevant articles for inclusion was conducted in two stages. First, titles and abstracts were reviewed and marked for inclusion or exclusion based on the search criteria outlined above. In cases where it was not possible to make a decision based on the abstract, the study was included for full text screening in the next stage. Following general recommendations regarding the review of abstracts (Stoll et al., 2019; Waffenschmidt et al., 2019), all titles and abstracts were reviewed by both authors. In the second stage, full texts for all studies included were reviewed for eligibility by both authors. Any uncertain cases were resolved through discussion between the authors.

\subsubsection{Coding scheme}

All studies that meet the eligibility criteria were coded based on key study characteristics, methodological strategy, measurement, and effect sizes, including sign and significance. Each paper was coded by both authors, and any disagreements were resolved through discussion. In regard to methodological strategy, we coded the following characteristics: design (e.g. difference-in-differences, propensity score matching, regression discontinuity, OLS), assumptions addressed (excludability, ignorability), sample size (control, treatment), and temporal window (in days). Regarding the assumptions addressed, we evaluated the extent to which studies checked threats to the excludability and ignorability assumptions. Following the recommended practices by Munoz et al. (2020), we evaluated the ignorability assumption based on whether or not researchers conducted balance tests, assessed multiple bandwidths, adjusted covariates for imbalances, and examined non-response patterns. We evaluated the excludability assumption based on whether or not they estimated placebo treatment effects, assessed pre-existing time-trends, and conducted falsification tests on other units and on other outcomes. In addition, we examined to what extent they provided an in-depth description of the event. The full coding scheme is available in the Online Appendix.

\subsubsection{Data synthesis}

Given the differences across event type and hypothesized effects, we opted for a narrative review of studies' results and methodological characteristics. The synthesis is divided into two parts: first, we describe the types of events, hypothesized effects on trust in police, and the methodological characteristics of each study 
including an evaluation as to what extent the key assumptions (ignorability, excludability) are addressed. Second, we summarize the findings of each study.

\subsubsection{Deviation from the protocol}

It was our primary intention to exclude studies with "procedural justice" as an outcome (see preregistration). Given the low $\mathrm{n}$ of studies, and the conceptual similarities of procedural justice and trust/trustworthiness/confidence, as well as the comments by the peer reviewers, we decided to deviate from the protocol and include studies using procedural justice (i.e., Curtice, 2021).

\section{Results}

The search of databases resulted in 2,633 studies. Figure 1 shows the search and identification process in a PRISMA flowchart (see Page et al., 2021). Following the removal of duplicates $(n=823)$, the abstracts of the remaining 1,810 studies were screened by both authors based on the inclusion criteria. A total of 55 potential studies were retrieved for full-text screening ( $n=41$ from database searches, $n=14$ from the search of reference lists and citations). Next, the texts were reviewed to assess eligibility. The three main reasons for exclusion were that the study utilized a before and after design $(n=17)$, the outcome was not attitudinal or did not measure trust/confidence in the police or procedural justice $(n=12)$, and the study did not contain an unexpected event $(\mathrm{n}=9)$. The final sample included 12 independent studies.

\subsection{Characteristics of the included studies}

Of the 12 identified studies that assess an unexpected event during survey design, half $(\mathrm{n}=6)$ were published in the last two years (since 2019) and the oldest was published in 2012. The geographical setting of the studies is relatively diverse, including the United States $(n=2)$, United Kingdom $(n=2)$, Spain $(n=1)$, France $(\mathrm{n}=1)$, Russia $(\mathrm{n}=1)$, New Zealand $(\mathrm{n}=1)$, Zimbabwe $(\mathrm{n}=1)$, Uganda $(\mathrm{n}=1)$, and Afghanistan $(\mathrm{n}=1)$. Only one study took a cross-national approach, assessing unexpected events (protests) across 13 African countries. A summary of the included studies, events, and results is presented in Table 1.

\subsubsection{Types of events and hypothesized effects}

The types of events can be grouped into three broad categories (see Table 1). The first group of events capture incidents of police violence $(\mathrm{n}=6)$, typically as a stand-alone high-profile event (e.g. violence against or death of a minority group member, political repression). In two studies, the focus of the event was on mass mobilization or disorder that followed high-profile incidents of police violence (i.e. the 2012 London disorder following the death of Mark Duggan, the 2020 protests following the death of George Floyd). In all but one of these studies, the authors hypothesized that experiences of police violence would result in more negative perceptions of the police. One study did not provide a hypothesis (Hohl et al., 2013). Conversely, one study assessed the impact of peaceful protest policing following contested government elections (Frye \& Borisova, 2019). The expectation was that the use of peaceful instead of repressive treatment of protesters would lead to more trust in police.

The second group of events concern external threats or crises, most notably terrorist attacks $(\mathrm{n}=3)$ and the COVID-19 pandemic and lockdown $(n=1)$. The terrorist incidents include the 2012 Taliban attack on a hotel in Kabul, Afghanistan, the 2004 Madrid train bombings, and a variety of domestic (UK) and international (Continental European) terrorist attacks. For both the terrorist and pandemic events, the authors hypothesized that trust in police would increase in line with "rally-round-the-flag" effects. 


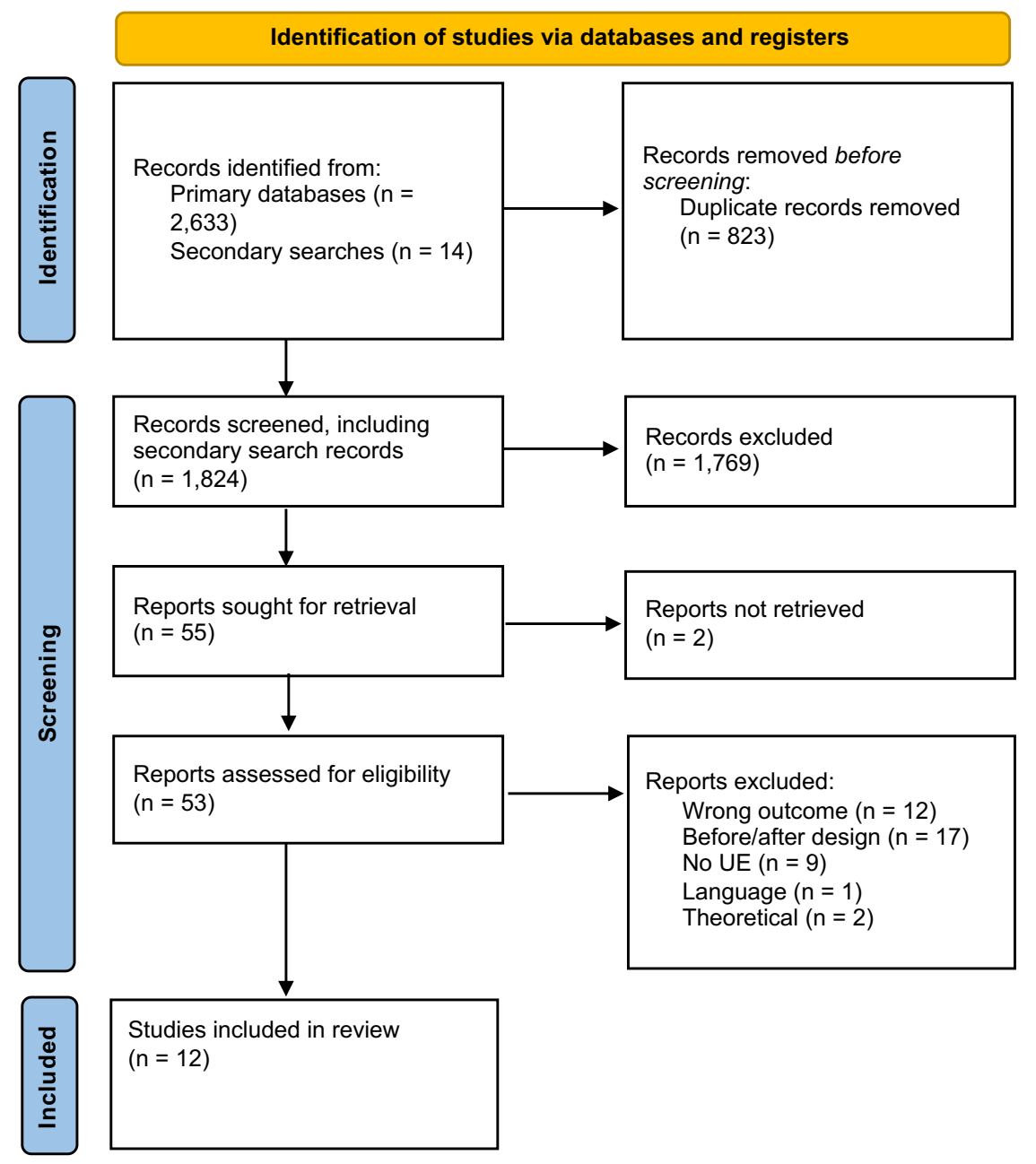

Figure 1: PRISMA flowchart showing the search and identification of studies.

Finally, two studies examined events that do not fit well into the previous two categories. One study examined the effect of political protests on trust in police, arguing that protests signal to citizens that state institutions are not doing their job monitoring political actors or providing services (Sangnier \& Zylberberg, 2017). Another study examined the impact of incidents of political repression on trust in institutions, including a measure of trust in police (García-Ponce \& Pasquale, 2015). However, they hypothesize that this will lead to higher trust in police because respondents fear political reprisal.

\subsection{Methodological characteristics and assessment}

\subsubsection{Research Design}

While all studies examined unexpected events that occurred during survey fieldwork, they adopted a wide range of designs and analytical methods to answer their research questions (see Table 2). The majority utilized some form of linear or ordered logit regression $(n=6)$, sometimes as an additional analysis alongside 
Table 1: Summary of study characteristics and results

\begin{tabular}{|c|c|c|c|c|c|}
\hline Author(s) & Year & Location & Unexpected event & Data source & $\begin{array}{l}\text { Hypothesized effects } \\
\text { (mechanism) }\end{array}$ \\
\hline Curtice & 2021 & Uganda & $\begin{array}{l}\text { Violent political } \\
\text { repression }\end{array}$ & Twaweza/Ipsos & $\begin{array}{l}\text { less procedural justice } \\
\text { (legitimacy) }\end{array}$ \\
\hline $\begin{array}{l}\text { Deglow \& } \\
\text { Sunderberg }\end{array}$ & 2021 & $\begin{array}{l}\text { Kabul, } \\
\text { Afghanistan }\end{array}$ & $\begin{array}{l}\text { Terrorist attack on } \\
\text { hotel }\end{array}$ & $\begin{array}{l}\text { Survey of the Afghan } \\
\text { People }\end{array}$ & $\begin{array}{l}\text { more trust (rally), less } \\
\text { trust (performance) }\end{array}$ \\
\hline $\begin{array}{l}\text { Dinesen \& } \\
\text { Jaeger }\end{array}$ & 2013 & Spain & $\begin{array}{l}2004 \text { Madrid train } \\
\text { bombing }\end{array}$ & Eurobarometer & more trust (rally) \\
\hline $\begin{array}{l}\text { Fenn \& } \\
\text { Brunton-Smith }\end{array}$ & 2021 & London, UK & $\begin{array}{l}\text { Domestic and } \\
\text { international terrorist } \\
\text { attacks }\end{array}$ & $\begin{array}{l}\text { Metropolitan Police } \\
\text { Attitudinal Survey }\end{array}$ & $\begin{array}{l}\text { more trust (rally), less } \\
\text { trust (performance) }\end{array}$ \\
\hline Frye \& Borisova & 2019 & $\begin{array}{l}\text { Moscow, } \\
\text { Russia }\end{array}$ & $\begin{array}{l}\text { Allowing (peaceful) } \\
\text { government protests }\end{array}$ & Authors' own survey & more trust (legitimacy) \\
\hline $\begin{array}{l}\text { Garcia-Ponce \& } \\
\text { Pasquale }\end{array}$ & 2015 & Zimbabwe & $\begin{array}{l}\text { Violent political } \\
\text { repression }\end{array}$ & Afrobarometer & $\begin{array}{l}\text { more trust } \\
\text { (falsification) }\end{array}$ \\
\hline Hohl et al. & 2012 & London, UK & 2011 London disorder & $\begin{array}{l}\text { Metropolitan Police } \\
\text { Attitudinal Survey }\end{array}$ & less trust (legitimacy) \\
\hline Naegel \& Lutter & 2021 & France & $\begin{array}{l}\text { Police violence against } \\
\text { black man in Paris, } \\
\text { subsequent riots }\end{array}$ & $\begin{array}{l}\text { European Social } \\
\text { Survey }\end{array}$ & less trust (legitimacy) \\
\hline $\begin{array}{l}\text { Reny \& } \\
\text { Newman }\end{array}$ & 2021 & USA & $\begin{array}{l}\text { Protest police violence } \\
\text { (death of George } \\
\text { Floyd) }\end{array}$ & Nationscape Survey & $\begin{array}{l}\text { less trust (legitimacy), } \\
\text { null (long-term) }\end{array}$ \\
\hline $\begin{array}{l}\text { Sangnier \& } \\
\text { Zylberberg }\end{array}$ & 2017 & $\begin{array}{l}13 \text { African } \\
\text { countries }\end{array}$ & Government protests & Afrobarometer & $\begin{array}{l}\text { less trust } \\
\text { (performance) }\end{array}$ \\
\hline Sibley et al. & 2020 & New Zealand & Covid-19 lockdown & $\begin{array}{l}\text { New Zealand Attitudes } \\
\text { and Values Survey }\end{array}$ & more trust (rally) \\
\hline White et al. & 2018 & $\begin{array}{l}\text { Baltimore, } \\
\text { USA }\end{array}$ & $\begin{array}{l}\text { Police violence (death } \\
\text { of Freddie Gray) }\end{array}$ & $\begin{array}{l}\text { National Institute on } \\
\text { Drug Abuse survey }\end{array}$ & $\begin{array}{l}\text { less trust (legitimacy), } \\
\text { null (long-term) }\end{array}$ \\
\hline
\end{tabular}

Note:

The mechanism of the hypothesized effect(s) are reported in parentheses. 'Rally' refers to rally-round-the-flag effects, 'performance' refers to judgements based on police performance, 'legitimacy' refers to updating mechanisms based on police procedural and distributive justice, 'long-term' refers to the notion that attitudes are developed early and stable long-term, and 'falisfication' refers to falsified responses based on fear. NR=not reported.

either regression discontinuity designs $[\mathrm{RDD}]$ or difference-in-differences $[\mathrm{DiD}]$ designs $(\mathrm{n}=2) \mathrm{L}^{2}$ Two studies utilized propensity score matching in combination with paired sample t-tests to estimate the mean differences in trust in police between pre- and post-event groups $(n=2)$. One study aggregated responses by day and estimated the impact of the event using interrupted time series analyses [ITS]. In one study, the proportion of responses in a given category were compared before and after the event (Hohl et al., 2013). However, it is not entirely clear what type of analysis or method was used to estimate differences.

\footnotetext{
${ }^{2}$ The DiD design is based on the idea of extending the simple before-after comparison of a treatment group by a before-after comparison with a control group. The difference at time 2 (after the intervention/event) between the treatment and the control group is subtracted from the difference between the treatment and control group at time 1 (before the intervention/event). With approximate equivalence of the groups, it is thus possible to control for unobserved factors that might influence the outcome in both the control and the treatment group. The RDD, on the other hand, exploits the fact that a continuous variable, in the case of the UESD this is the date, assigns observations to either control or treatment group. As a result, observations very close to the cut-off should be comparable to each other in the sense of a quasi-random assignment, and the average differences in the outcome should be attributable to the treatment, conditional on certain testable assumptions (Skovron \& Titiunik, 2015). A crucial advantage of the RDD compared to the standard before-after estimator is the possibility to determine non-arbitrary bandwidths (i.e. timeframes) to evaluate local effects (Imbens \& Kalyanaraman, 2012).
} 
A PREPRINT - April 4, 2022

Table 2: Summary of sample characteristics and temporal window used to assess treatment

\begin{tabular}{lllll}
\hline Author(s) & Control N & Treatment N & Design & $\begin{array}{l}\text { Temporal window } \\
\text { post-event (days) }\end{array}$ \\
\hline Curtice & & & Regression & 9 \\
Deglow \& Sunderberg & 1789 & 131 & Regression & 6 \\
Dinesen \& Jaeger & 928 & 318 & Regression & 7 \\
Fenn \& Brunton-Smith & NR & NR & ITS & $182-2445(\mathrm{a})$ \\
Frye \& Borisova & 611 & 939 & Regression & 15 \\
Garcia-Ponce \& Pasquale & NR & NR & Regression & 10 \\
Hohl et al. & NR & NR & NR & $53(\mathrm{~b})$ \\
Naegel \& Lutter & 1853 & 207 & RDD & $3,6,13$ \\
& & & Regression & 37 \\
Reny \& Newman & NR & NR & RDD & 7 \\
& & & Regression & 98 \\
Sangnier \& Zylberberg & NR & NR & DiD & 60 \\
Sibley et al. & 1003 & 1003 & PSM+t-test & 18 \\
White et al. & 259 & 1269 & PSM+t-test & $134(\mathrm{~b})$ \\
\hline
\end{tabular}

Note:

$\mathrm{NR}=$ not reported; Regression=OLS, logit, or probit regression; ITS=interrupted time series; $\mathrm{RDD}=$ regression discontinuity design, bandwidth reported for temporal window; $\mathrm{DiD}=$ difference-in-differences; $\mathrm{PSM}=$ propensity score matching.

${ }^{a}$ Multiple events analyzed, so $\mathrm{N}$ and temporal windows varied depending on event date. Range calculated by based on dates of events and fieldwork provided in the study;

b Temporal window calculated by based on the date of the event and fieldwork provided in the study.

\subsubsection{Sample characteristics}

One important methodological characteristic is the size of the sample for the "treatment" (post-event) and "control" (pre-event) groups. In a UESD study the size of these groups is dependent on the timing of the event during fieldwork. As such, if the event occurs very early or late during fieldwork, the difference in the size of the groups may be large, which can result in methodological issues that need to be addressed (e.g. power, heteroskedasticity). This is the case in the study analyzing the impact of the Madrid train bombings (Dinesen \& Jaeger, 2013), wherein the event occurred 7 days before the completion of the Eurobarometer fieldwork. As a result, the treatment sample consisted of 72 respondents. The size of these groups may also depend on the chosen design. For example, the selection of an optimal bandwidth (e.g by a mean square error [MSE] approach) in RDDs can restrict the analytical sample to only a small number of days before and after the event (e.g., 6 days, $\mathrm{n}=130$ in Nägel \& Lutter, 2021). Those using RDD therefore typically assess multiple bandwidths to ensure robust results (Stommes et al., 2021). Both papers applying a RDD in this review are using a non-parametric automated MSE bandwidth selection method.

Two studies did not report the sample size for control and treatment groups (Hohl et al., 2013; Reny \& Newman, 2021). Two studies used events with varying timing and location (violent political repression, protests), which implies variation in the size of treatment and control groups per event (García-Ponce \& Pasquale, 2015; Sangnier \& Zylberberg, 2017). However, in both of these studies the size or average size of each treatment and control group was not reported. In three studies, the size of the treatment and control groups were relatively balanced, with one study using 1-to-1 matching to achieve balanced pre- and post-event groups. The remaining studies reported relatively large differences in the size of treatment and control groups. 
A PREPRINT - April 4, 2022

Table 3: Evaluation of ignorability and excludability assumptions

\begin{tabular}{|c|c|c|c|c|c|c|c|c|c|c|}
\hline \multirow[b]{2}{*}{ Author(s) } & \multicolumn{4}{|c|}{ Ignorability } & \multicolumn{4}{|c|}{ Excludability } & \multirow{2}{*}{$\begin{array}{c}\text { Both } \\
\begin{array}{l}\text { Event de- } \\
\text { scription }\end{array}\end{array}$} & \multirow[b]{2}{*}{ Score } \\
\hline & $\begin{array}{l}\text { Balance } \\
\text { tests }\end{array}$ & $\begin{array}{l}\text { Multiple } \\
\text { band- } \\
\text { widths }\end{array}$ & $\begin{array}{l}\text { Covariate } \\
\text { adjust- } \\
\text { ment }\end{array}$ & $\begin{array}{l}\text { Non- } \\
\text { response }\end{array}$ & $\begin{array}{l}\text { Placebo } \\
\text { treat- } \\
\text { ments }\end{array}$ & $\begin{array}{l}\text { Pre- } \\
\text { existing } \\
\text { time } \\
\text { trends }\end{array}$ & $\begin{array}{l}\text { Fals. tests } \\
\text { (other } \\
\text { units) }\end{array}$ & $\begin{array}{l}\text { Fals. tests } \\
\text { (other } \\
\text { outcomes) }\end{array}$ & & \\
\hline Curtice & 1 & 0 & 1 & 0 & 1 & 0 & 0 & 1 & 1 & 5.00 \\
\hline $\begin{array}{l}\text { Deglow \& } \\
\text { Sunderberg }\end{array}$ & 1 & 1 & 1 & 1 & 1 & 1 & 1 & 0 & 1 & 8.00 \\
\hline Dinesen \& Jaeger & 1 & 1 & 1 & 0 & 0 & 0 & 0 & 0 & 1 & 4.00 \\
\hline $\begin{array}{l}\text { Fenn \& } \\
\text { Brunton-Smith }\end{array}$ & 1 & 0 & 1 & 0 & 0 & 1 & 0 & 0 & 1 & 4.00 \\
\hline Frye \& Borisova & 1 & 1 & 1 & 1 & 0 & 0 & 1 & 1 & 1 & 7.00 \\
\hline $\begin{array}{l}\text { Garcia-Ponce \& } \\
\text { Pasquale }\end{array}$ & 1 & 1 & 1 & 1 & 0 & 0 & 0 & 0 & 1 & 5.00 \\
\hline Hohl et al. & 0 & 0 & 0 & 0 & 0 & 0 & 0 & 0 & 0 & 0.00 \\
\hline Naegel \& Lutter & 1 & 1 & 1 & 0 & 1 & 0 & 1 & 1 & 1 & 7.00 \\
\hline Reny \& Newman & 1 & 1 & 1 & 1 & 1 & 1 & 0 & 1 & 1 & 8.00 \\
\hline $\begin{array}{l}\text { Sangnier \& } \\
\text { Zylberberg }\end{array}$ & 1 & 1 & 1 & 1 & 0 & 1 & 1 & 0 & 1 & 7.00 \\
\hline Sibley et al. & 1 & 0 & 1 & 0 & 0 & 0 & 0 & 0 & 1 & 3.00 \\
\hline White et al. & 1 & 1 & 1 & 0 & 0 & 1 & 0 & 0 & 1 & 5.00 \\
\hline $\begin{array}{l}\text { Count column } \\
\text { (out of 11) }\end{array}$ & 11 & 8 & 11 & 5 & 4 & 5 & 4 & 4 & 11 & 5.25 \\
\hline
\end{tabular}

\subsubsection{Assumptions addressed}

Table 3 provides an overview of the extent to which the included studies assessed or addressed the excludability and ignorability assumption. As has been described above, there are different strategies to test or control for possible violations. A "1" in Table 3 indicates that the respective study has performed this robustness analysis, whereas a "0" indicates that this specific test/check is missing from that paper. Both authors coded the included studies independently. A comparison of the coding results showed an overlap of $95.45 \%$ between both coders. Deviating assessments were discussed accompanied by a re-assessment of a particular test/check in the respective study to find a solution. Finally, a score was computed reflecting an additive index of all possible robustness checks ranging from 0-9. This score can be interpreted as the respective study's rigorousness in terms of the specific UESD assumptions.

Eleven out of twelve studies used balance tests, multiple bandwidths, and provided an in-depth description of the focal event. Most $(n=8)$ have extended a naïve before/after estimation by applying a model using control variables or matching procedures. Less than half of the included studies analyzed non-response patterns and/or pre-existing time-trends $(n=5)$. Four studies examined alternative observation units by estimating results using the same survey at the same time in other countries, and/or the same survey at a different time in the same country. Finally, only three investigated placebo treatments and falsification tests on other outcomes, namely by assessing effects on variables very similar to the actual outcomes that should theoretically not be affected by the treatment.

It is clear from Table 3 that the ignorability assumption, with the exception of the analysis of non-response patterns, is subjected to much more rigorous scrutiny than the excludability assumption. Out of 60 possible tests of the ignorability assumption $46(77 \%)$ were performed, while out of 60 possible tests of the excludability assumption only $27(45 \%)$ were performed.

\subsubsection{Summary of effects}

Given that the first two groups generally share similar theoretical frameworks and hypotheses, we summarize the effects of studies according to the categories discussed above (for summary of results, see Table 4). Two 
Table 4: Summary of effects

\begin{tabular}{|c|c|c|c|}
\hline Author(s) & Unexpected event & Result & $\begin{array}{l}\text { Effect size } \\
\text { significance }\end{array}$ \\
\hline Curtice & Violent political repression & less procedural justice & sig \\
\hline Deglow \& Sunderberg & Terrorist attack on hotel & more trust & sig \\
\hline Dinesen \& Jaeger & 2004 Madrid train bombing & more trust & sig \\
\hline Fenn \& Brunton-Smith & $\begin{array}{l}\text { Domestic and international } \\
\text { terrorist attacks }\end{array}$ & $\begin{array}{l}\text { more trust (Islamic), } \\
\text { less trust (right) }\end{array}$ & partial \\
\hline Frye \& Borisova & $\begin{array}{l}\text { Allowing (peaceful) government } \\
\text { protests }\end{array}$ & more trust & $\operatorname{sig}$ \\
\hline Garcia-Ponce \& Pasquale & Violent political repression & more trust & $\operatorname{sig}$ \\
\hline Hohl et al. & 2011 London disorder & null & ns \\
\hline Naegel \& Lutter & $\begin{array}{l}\text { Police violence against black } \\
\text { man in Paris, subsequent riots }\end{array}$ & less trust & sig \\
\hline Reny \& Newman & $\begin{array}{l}\text { Protest police violence (death of } \\
\text { George Floyd) }\end{array}$ & more negative views & $\operatorname{sig}$ \\
\hline Sangnier \& Zylberberg & Government protests & less trust & sig \\
\hline Sibley et al. & Covid-19 lockdown & more trust & sig \\
\hline White et al. & $\begin{array}{l}\text { Police violence (death of Freddie } \\
\text { Gray) }\end{array}$ & less trust & ns \\
\hline
\end{tabular}

Note:

ns=not significant; sig=significant at 0.05 level; partial=not all incidents significant.

out of six studies examining the effects of police violence did not find significant effects on trust in police (London disorder, Hohl et al., 2013; the death of Freddie Gray, White et al., 2018). Three of the remaining four studies found that incidents of police violence lead to significantly less trust in police (violence against Theo L. in Paris, Nägel \& Lutter, 2021; death of George Floyd, Reny \& Newman, 2021; violent repression by police in Uganda, Curtice, 2021), and the fourth found that peaceful protest policing was associated with increases in trust in police (peaceful protests in Russia, Frye \& Borisova, 2019). All four studies examining external threats or crises found to some extent significant "rally effects" on trust in police (attack on hotel in Kabul, Deglow \& Sundberg, 2021; Madrid train bombings, Dinesen \& Jaeger, 2013; various domestic and international attacks, Fenn \& Brunton-Smith, 2021; COVID-19 lockdown in New Zealand, Sibley et al., 2020). One study assessed a wide range of domestic and international terrorist attacks that occurred within a particular time frame (2011-2018, Fenn \& Brunton-Smith, 2021). When all domestic and international attacks are included in the model, the effect of terrorist attacks lead to increases in support for the police after only three out of the five domestic (UK) Islamic incidents.

The remaining two studies both found effects consistent with their hypotheses. Protest incidents across 13 African countries were associated with significantly less trust in police (Sangnier \& Zylberberg, 2017). Violent political repression in Zimbabwe was associated with increases in trust in police, which was explained by the respondents' fear of political consequences from the Mugabe regime (García-Ponce \& Pasquale, 2015).

\section{Discussion}

Given the number of ongoing large-scale surveys across countries, it is likely that researchers will increasingly take advantage of the UESD approach to assess the causal impact of relevant high-profile events on criminological outcomes. The current systematic review focused on studies that utilized UESD to evaluate the impact of events on trust in police, and the methodological findings are informative for any researchers interested in applying UESD to assess causal effects on an outcome of interest. Specifically, we highlight four 
important findings broadly concerning the substantive effects of events on trust in police, issues related to design and power, and the evaluation of assumptions to detect threats to internal validity.

First, our synthesis found evidence that public trust in police does change following high-profile events, but these effects are not consistent across events and contexts. Three out of five studies that evaluated incidents of police violence found significant negative effects on trust, whereas three out of four that evaluated major crises (e.g. terrorist attacks) found positive "rally" effects on trust in police. While the current narrative review approach does not allow us to quantitatively examine which factors may account for these mixed results, one possible explanation may be due to the prior level of institutional trust and contextual setting in which the event takes place. In relation to legitimacy mechanisms, some policing researchers have noted that in order to affect and observe change in trust in police, levels of trust among the public must first be at a level amenable to change (White et al., 2018). White et al. (2018) for example suggested that their null results on trust following the death of Freddie Gray may be because levels of legitimacy and trust in police in Baltimore were already low resulting in a "floor effect" whereby public opinion could not decline much further. Other research in "high-trust" societies has found that negative policing events were not associated with substantive changes in trust (Kääriäinen et al., 2016; Thomassen et al., 2014). The authors in these studies suggest this may be due to already high "reserves" of trust in police prior to the events. More research is needed to understand how societal and institutional characteristics may shape public response to high-profile, vicarious incidents involving the police.

The "asymmetry hypothesis," which is rooted in theories of negativity bias (Rozin \& Royzman, 2001), suggests that negative experiences with the police trigger stronger public reactions than positive experiences with the police (Skogan, 2006). While there is evidence to support asymmetry on the basis of personal encounters and media effects (Choi, 2021; Li et al., 2016), our review found that both positive (peaceful protest policing) and negative (police violence, repression) experiences influenced attitudes towards the police. However, we are not able to compare the relative size of the effect between positive and negative events. In addition, most studies on vicarious experiences in our review focused on negative events. Only one study assessed the effects of positive encounters, i.e. the 'unexpected' peaceful policing of anti-government protests in Russia (Frye \& Borisova, 2019). It is therefore not yet possible to judge to what extent more positive "trust-generating" incidents influence public opinion (or not). Future research should assess more positive or neutral events in order to appropriately evaluate possible asymmetric effects of police actions or policies on public opinion.

Additionally, given the wide range of attention to assessing causal assumptions, it is difficult to draw conclusions about the causal impact of vicarious experiences or crises on attitudes towards police. However, the five studies that scored relatively high on checking assumptions ( $\geq 7$ out of 9 ) do find significant changes in trust in police following incidents of police (non) violence and protest (Frye \& Borisova, 2019; Nägel \& Lutter, 2021; Reny \& Newman, 2021), protests against the government (Sangnier \& Zylberberg, 2017), and a terrorist attack (Deglow \& Sundberg, 2021). With regard to the procedural justice framework, this provides some causal evidence that vicarious (positive and negative) experiences can shape public trust in police (Nagin \& Telep, 2020). However, it is unclear to what extent these effects are lasting (Nägel \& Lutter, 2021; Reny \& Newman, 2021).

Second, we found substantial heterogeneity in research designs across the twelve studies included in the review. This includes choices regarding analytical approach, whereby studies applied a wide range of tools, including difference-in-differences design, regression discontinuity design, OLS regression, and propensity score matching with paired-sample t-tests. While these analytical approaches are valid for estimating treatment effects, some are better equipped than others to assess and minimize threats to internal validity and therefore estimate causal treatment effects. For example, while propensity score matching and mean comparisons allows one to control for observed differences between groups, the validity of the results depend on the choice of covariates to be matched (Guo et al., 2020; King \& Nielsen, 2019). 
When panel data are available, the difference-in-differences design can add confidence in the validity of the design because it is possible to control, for example, for seasonal patterns in the outcomes of interest. It is not entirely implausible that trust in the police may be influenced by certain annual events, for example, by the May Day Rallies against police in Germany 3 Given a panal data set, it would be possible to operationalize the treatment group using a binary indicator (before and after each day of the event) independent of the survey year, while including a time dummy for the year. The treatment effect $\delta$ could then be modeled as an interaction effect in the form $\delta\left(\right.$ Treatment $_{i t}$ Time $\left._{t}\right)$, thus controlling for seasonal time trends. This modeling strategy would allow one to estimate the difference-in-differences outlined above, while simultaneously controlling for covariates.

In a similar vein, the decentralized institutional organization of police forces in several countries (e.g., US, Germany) can be exploited to analyze the effect of exclusively locally relevant events while using other regions as control groups. For example, a specific policing event or policy change in one federal state might affect local attitudes within that state but not in all other federal states, which can be used as control groups in a DiD design. The effect of interest could then be modelled as the slope coefficient of the interaction between a before/after indicator and a dummy of the federal state of interest. The most relevant additional assumption in such a design is the parallel trends assumption which implies that if there had been no event or policy change in the federal sate of interest, the mean difference between treatment and control group should have stayed unchanged in the post-treatment period as it was in the pre-treatment period (Huntington-Klein, 2022). ** With cross-sectional data, the regression discontinuity approach can enhance internal validity because it allows for a quasi-random assignment between treatment and control group (Bor et al., 2014).

Recent comparisons showed that the regression discontinuity design is comparable to randomized controlled trials in terms of internal and external validity (Chaplin et al., 2018). As Stommes et al. (2021) discuss, this might still be conditional on having enough observations in the vicinity of the cut-point. Following their advice, we therefore recommend the use of the regression discontinuity design with automated bandwidth selection procedures and alongside a more traditional before/after setup. Given the limited bandwidth in the regression discontinuity analysis, a more straightforward regression approach would also allow one to examine the development of treatment effect by adding day or a week dummies step-by-step to estimate long-term vs. short-term effects.

Third, Table 2 shows rather large differences between treatment and control group which raises concerns about the equal distribution of residual variances. We recommend checking for issues of heteroscedasticity and the use of robust standard errors where applicable. As a general procedure, we suggest computing both heteroscedasticity robust and homoskedasticity-only robust standard errors and to report the more conservative ones (Angrist \& Pischke, 2009).

Relatedly, certain elements of the design, such as the size of the treatment and control groups, are often out of the researcher's control since they are determined by the timing of the event during fieldwork. As has been described, our review showed that for some studies the size of the treatment and control groups were highly unbalanced. For example, in one study the event occurred 7 days before the end of survey fieldwork, resulting in $\mathrm{n}=72$ for the treatment group (Dinesen \& Jaeger, 2013). Such differences in group size may result in insufficient power to detect an effect, particularly if researchers are interested in evaluating shortvs. long-term effects using different temporal windows. Since increasing the sample size is usually not possible, statistical power analyses such as sensitivity analysis can be useful to determine the minimum size of the effect that can be detected reliably given a fixed alpha, the available sample size, and desired power level (Perugini et al., 2018).

\footnotetext{
${ }^{3}$ See: https://www.dw.com/en/may-day-rallies-police-protesters-clash-in-berlin-paris/a-57395625.
} 
Post hoc or retrospective power analyses using observed effect sizes are not advisable, as the results can be misleading (Faul et al., 2007). Calculating the minimum detectable effect size allows the researcher (and reader) to judge to what extent the range of effect sizes can be considered realistic given existing knowledge (Perugini et al., 2018). Effect sizes that are larger than the minimum detectable value may occur due to chance, but also may be a signal that the result is upwardly biased (Lakens, 2021). Sensitivity analyses can be computed easily using available power analysis programs such as G*Power (Faul et al., 2007). For example, a hypothetical survey in which the unexpected event occurred later during fieldwork may result in sample group sizes of $n=500$ in the control (pre-event) and $n=50$ (post-event). A sensitivity analysis specifying a desired power level of 0.80 and alpha of 0.05 for a (two-tailed) test of mean differences would be able to detect a minimum effect size of $\mathrm{d}=0.42$. This means that for unbalanced groups with small sample sizes, the observed effect must be relatively large in order to be statistically significant (Lakens, 2021).

Finally, our result show that the ignorability assumption is addressed more often and more rigorously by the included studies than is the excludability assumption. In particular, studies often failed to evaluate placebo treatments and conduct falsification tests on other units and outcomes (see Table 3). The falsification checks for example are essential to rule out the possibility that the outcome might be affected by another event related to the timing of the fieldwork (Muñoz et al., 2020). Our advice in this instance is twofold: first, studies applying this particular research design should follow the good-practice recommendations as closely as possible (see Legewie, 2013; Muñoz et al., 2020). The reliability of the UESD can, where appropriate data are accessible, be improved by RD or DiD identification strategies. In this case, however, it is imperative that researchers adhere to the specifications of the relevant literature (Angrist \& Pischke, 2009; Skovron \& Titiunik, 2015), as the RDD in particular has shown to be prone to power issues, rendering findings either exaggerated or spurious (Stommes et al., 2021).

Second, journal editors and peer reviewers should carefully check to what extent researchers have systematically evaluated UESD assumptions, in particular concerning excludability. These assumptions are essential to check because there are many reasons why estimates can be biased in quasi-experimental designs that use observational data (Gangl, 2010).

To summarize, the UESD approach is of particular interest for criminological contexts, as experimental manipulation of relevant stimuli is often ethically impossible. Additionally, there are many theoretical reasons why events could affect public perceptions of police differently - especially given the various geographical contexts of the included studies - underlining the need for continuous research that allows a comparative perspective. Based on this discussion, and to facilitate the rigorous application of the design within this strand of research, we provide a best-practice guide that summarizes our recommendations for the application of UESD regardless of context, as well as some general suggestions:

1. Prioritize events. The overlap of events with relevant surveys should be assessed first, as opposed to scanning relevant surveys for overlap with events. This can ensure that the feasibility of a study does not become more important than its relevance (see Deaton (2010) for a comparable discussion regarding natural experiments in general).

2. Pre-register studies. If possible, the study should be pre-registered to avoid hypothesizing after the results are known, i.e., "harking" (Kerr, 1998).

3. Conduct sensitivity power analyses. Sensitivity power analyses should be conducted a priori to calculate the minimum effect size that is likely to be detected given the before/after sample sizes. This can inform researchers about whether their UESD setup is well suited to answer the specific research question.

4. Use appropriate standard errors. Heteroscedasticity might play a substantial role when before/after sample sizes and characteristics differ substantially. Accordingly, both homoscedasticity-only and 
heteroscedasticity robust standard errors should be computed while reporting the more conservative ones in the manuscript.

5. Evaluate assumptions. If possible, all tests proposed by Munoz et al. should be performed to evaluate the Ignorability and Excludability assumptions (see Table 3).

6. Use alternative methods for robustness checks. DiD or RDD extensions can be employed in the fashion outlined above but only alongside a more straightforward UESD approach to avoid model dependence.

7. Consider potential heterogeneous treatment effects. When there are potentially heterogenous effects that are not included, this could be a source of omitted variable bias. However, it is important to ensure that potential interactions are modelled from covariates that could theoretically not be outcome variables themselves (e.g., ethnicity, gender, etc.).

\subsection{Limitations}

It is important to note that while the current study focused on the outcome trust in police to improve comparability, this meant that a number of other comparable studies with related outcomes were excluded from the analysis (Curtice \& Behlendorf, 2021; Oglesby-Neal et al., 2019; Turchan, 2021). Similarly, papers that did not meet the inclusions criteria because they did not correspond to the definition of UESD by Muñoz et al. were also excluded. For example, Revkin (2022) provides an empirical examination on whether respondents adopt their attitudes toward the police after the extremely violent and lethal repression of anti-government demonstrations in Iraq, finding a decrease in perceptions of federal but not local police who did not participate as excessively in repressing protestors. However, the paper relies on an analysis of attitudinal differences between two survey waves, rather than an analysis of an event occurring within the fieldwork period of a single survey, making it impossible to assess multiple bandwidths, placebo treatments or pre-existing time trends. Researchers should continue to critically and systematically assess the validity of causal inferences in studies using observational data in order to highlight good practice for a given research question, design, and data type.

In addition, the UESD requires that the event should occur during fieldwork, whereas events are very likely to occur outside of fieldwork or between two waves of data collection (Kochel, 2019). Although the UESD is better equipped to address threats to internal validity, such as collateral events and selection bias, events that occur between waves of data collection among the same participants have the advantage of assessing within-person changes controlling for stable between-person characteristics (see e.g. Kochel, 2019; LaFree \& Adamczyk, 2017).We recommend to adjust for unobserved unit-specific and time-specific confounders using a two-way-fixed-effects modeling strategy even though this does not represent a design-based estimation strategy (Imai \& Kim, 2021) that can yield similar confidence in the results as the straightforward UESD.

Another key problem in almost all UESD studies is the restriction to only capturing short term effects since fieldwork periods seldom span more than a few months. Ongoing surveys like the British "Metropolitan Police Public Attitudes Survey" or the American "Nationscape Survey" might, however, provide a more long-term perspective.

Although all but one (Frye \& Borisova, 2019) of the included studies relate to generally "negative" events, it should be noted that the quasi-experimental stimuli employed in the UESD setup need not be a crisis moment. An unexpected election outcome, the sudden retirement of a police chief, or a successful law enforcement operation that is discussed in the media could relate to outcomes of interest. Accordingly, our sample provides only limited variation since even the events that are hypothesized to increase public perceptions of police are understood to be crisis moments. 
We want to stress that only $25 \%$ of the included studies (Curtice, 2021; Deglow \& Sundberg, 2021; Nägel \& Lutter, 2021) cited the Muñoz et al. paper, which for the first time outlined the UESD approach. While this raises the question whether the other included papers can be classified as UESD, we are confident that this classification is appropriate for several reasons: First, most of the papers were published prior to (Muñoz et al., 2020), making it impossible for the researchers to cite the paper. Second, we adhere closely to the selection criteria which considered survey-based studies with an unexpected event during the fieldwork period used as treatment, i.e., the definition of the UESD provided by Muñoz and colleagues. Lastly, Muñoz et al. cite one of the included studies (Dinesen \& Jaeger, 2013) as an example UESD, increasing our confidence that our classifications of studies are generally comparable.

\subsection{Conclusions}

Increasingly, scholars have emphasized the need for caution in interpreting causal effects in policing research that relies on observational data (Cook, 2015; Graziano, 2019; MacCoun, 2005). For example, in procedural justice research, Nagin and Telep (2017, p. 7) argued that in order to credibly establish causality, a "demonstration of an exogenous manipulation of actual behavior affecting perceptions of procedurally just treatment and perceptions of legitimacy and ultimately legal compliance is necessary." On the one hand, the UESD can provide the solution to these issues provided that (a) fieldwork periods for adequate survey data, ideally including more refined survey instruments than a single trust indicator, overlap with relevant policing events, and (b) studies adhere to rigorous methodological requirements. Alongside other design-based approaches to causal inference, the UESD can help to rule out "third common causes" and investigate issues of reversed causality that are common not only to research on trust in police (Nagin \& Telep, 2017) but also to criminological and policing research in general (Dezember et al., 2021; Sampson, 2010).

On the other hand, our review showed that there are a variety of potential biases that threaten the validity of research findings from UESD studies. This is because in natural experiments there is only limited control for confounding factors compared to randomized controlled trials. Our technical suggestions put forward in this paper should help to ensure that future research is conducted as rigorously as possible to obtain the full benefits of this research design. Furthermore, it is our ambition that the narrative synthesis of research findings will provide further theoretical insights that can inform future research to more adequately understand when, to what extent, and in which contexts high-profile events influence trust in and legitimacy of the police.

\section{References}

Angrist, J. D. (2006). Instrumental variables methods in experimental criminological research: What, why and how. Journal of Experimental Criminology, 2(1), 23-44. https://doi.org/10.1007/ s11292-005-5126-x

Angrist, J. D., \& Pischke, J. S. (2009). Mostly Harmless Econometrics: An Empiricist's Companion. Princeton University Press.

Ares, M., \& Hernández, E. (2017). The corrosive effect of corruption on trust in politicians: Evidence from a natural experiment. Research $\&$ Politics, 4 (2), 205316801771418. https://doi.org/10.1177/ 2053168017714185

Bol, D., Giani, M., Blais, A., \& Loewen, P. J. (2021). The effect of COVID-19 lockdowns on political support: Some good news for democracy? European Journal of Political Research, 60(2), 497-505. https://doi.org/10.1111/1475-6765.12401

Bor, J., Moscoe, E., Mutevedzi, P., Newell, M.-L., \& Bärnighausen, T. (2014). Regression Discontinuity Designs in Epidemiology: Causal Inference Without Randomized Trials. Epidemiology, 25(5), 729-737. https://doi.org/10.1097/EDE.0000000000000138 
Bove, V., Böhmelt, T., \& Nussio, E. (2021). Terrorism abroad and migration policies at home. Journal of European Public Policy, 28(2), 190-207. https://doi.org/10.1080/13501763.2020.1729227

Bushway, S. D., \& Apel, R. J. (2010). Instrumental Variables in Criminology and Criminal Justice. In A. R. Piquero \& D. Weisburd (Eds.), Handbook of Quantitative Criminology (pp. 595-612). Springer.

Chaplin, D. D., Cook, T. D., Zurovac, J., Coopersmith, J. S., Finucane, M. M., Vollmer, L. N., \& Morris, R. E. (2018). THE INTERNAL AND EXTERNAL VALIDITY OF THE REGRESSION DISCONTINUITY DESIGN: A META-ANALYSIS OF 15 WITHIN-STUDY COMPARISONS. Journal of Policy Analysis and Management, 37(2), 403-429. https://doi.org/10.1002/pam.22051

Cheng, T. (2021). Social media, socialization, and pursuing legitimation of police violence*. Criminology, 1745-9125.12277. https://doi.org/10.1111/1745-9125.12277

Choi, J. (2021). Asymmetry in media effects on perceptions of police: An analysis using a within-subjects design experiment. Police Practice and Research, 22(1), 557-573. https://doi.org/10.1080/15614263. 2020.1749624

Cook, P. J. (2015). Will the Current Crisis in Police Legitimacy Increase Crime? Research Offers a Way Forward. Psychological Science in the Public Interest, 16(3), 71-74. https://doi.org/10.1177/ 1529100615610575

Curtice, T. B. (2021). How Repression Affects Public Perceptions of Police: Evidence from a Natural Experiment in Uganda. Journal of Conflict Resolution, 65(10), 1680-1708. https://doi.org/10.1177/ 00220027211013097

Curtice, T. B., \& Behlendorf, B. (2021). Street-level Repression: Protest, Policing, and Dissent in Uganda. Journal of Conflict Resolution, 65(1), 166-194. https://doi.org/10.1177/0022002720939304

Dawson, A. (2018). Police Legitimacy and Homicide: A Macro-Comparative Analysis. Social Forces. https://doi.org/10.1093/sf/soy043

Deaton, A. (2010). Instruments, Randomization, and Learning about Development. Journal of Economic Literature, 48(2), 424-455. https://doi.org/10.1257/jel.48.2.424

Deglow, A., \& Sundberg, R. (2021). To Blame or to Support? Large-scale Insurgent Attacks on Civilians and Public Trust in State Institutions. International Studies Quarterly, 65(2), 435-447. https://doi.org/ 10.1093/isq/sqab021

Dezember, A., Stoltz, M., Marmolejo, L., Kanewske, L. C., Feingold, K. D., Wire, S., Duhaime, L., \& Maupin, C. (2021). The lack of experimental research in criminology - evidence from Criminology and Justice Quarterly. Journal of Experimental Criminology, 17(4), 677-712. https://doi.org/10.1007/ s11292-020-09425-y

Dinesen, P. T., \& Jaeger, M. M. (2013). The Effect of Terror on Institutional Trust: New Evidence from the 3/11 Madrid Terrorist Attack: Effect of Terror on Institutional Trust. Political Psychology, 34(6), 917-926. https://doi.org/10.1111/pops.12025

Eisner, M., \& Nivette, A. (2013). The Effects of Legitimacy on Crime: A Review. In J. Tankebe \& A. Liebling (Eds.), Legitimacy and Criminal Justice: An International Exploration (pp. 308-325). Oxford University Press.

Esaiasson, P., Sohlberg, J., Ghersetti, M., \& Johansson, B. (2021). How the coronavirus crisis affects citizen trust in institutions and in unknown others: Evidence from 'the Swedish experiment.' European Journal of Political Research, 60(3), 748-760. https://doi.org/10.1111/1475-6765.12419

Faul, F., Erdfelder, E., Lang, A.-G., \& Buchner, A. (2007). G*Power 3: A flexible statistical power analysis program for the social, behavioral, and biomedical sciences. Behavior Research Methods, 39(2), 175-191. https://doi.org/10.3758/BF03193146

Fenn, L., \& Brunton-Smith, I. (2021). The effects of terrorist incidents on public worry of future attacks, views of the police and social cohesion. The British Journal of Criminology, 61(2), 497-518. https: //doi.org/10.1093/bjc/azaa070 
Frye, T., \& Borisova, E. (2019). Elections, Protest, and Trust in Government: A Natural Experiment from Russia. The Journal of Politics, 81(3), 820-832. https://doi.org/10.1086/702944

Gaines, B. J. (2002). Where's the Rally? Approval and Trust of the President, Cabinet, Congress, and Government Since September 11. Political Science 83 Politics, 35(03), 531-536. https://doi.org/10. $1017 /$ S1049096502000793

Gangl, M. (2010). Causal Inference in Sociological Research. Annual Review of Sociology, 36(1), 21-47. https://doi.org/10.1146/annurev.soc.012809.102702

García-Ponce, O., \& Pasquale, B. (2015). How Political Repression Shapes Attitudes Toward the State: Evidence from Zimbabwe. Pre-Print, 42.

Graziano, L. M. (2019). News media and perceptions of police: A state-of-the-art-review. Policing: An International Journal, 42(2), 209-225. https://doi.org/10.1108/PIJPSM-11-2017-0134

Guo, S., Fraser, M., \& Chen, Q. (2020). Propensity Score Analysis: Recent Debate and Discussion. Journal of the Society for Social Work and Research, 11(3), 463-482. https://doi.org/10.1086/711393

Hetherington, M. J., \& Nelson, M. (2003). Anatomy of a Rally Effect: George W. Bush and the War on Terrorism. Political Science and Politics, 36(01), 37-42. https://doi.org/10.1017/S1049096503001665

Hohl, K., Stanko, B., \& Newburn, T. (2013). The Effect of the 2011 London Disorder on Public Opinion of Police and Attitudes Towards Crime, Disorder, and Sentencing. Policing, 7(1), 12-20. https: //doi.org/10.1093/police/pas055

Hough, M., Jackson, J., Bradford, B., Myhill, A., \& Quinton, P. (2010). Procedural Justice, Trust, and Institutional Legitimacy. Policing, 4(3), 203-210. https://doi.org/10.1093/police/paq027

Huntington-Klein, N. (2022). The effect: An introduction to research design and causality (First edition). CRC Press, Taylor \& Francis Group. https://doi.org/10.1201/9781003226055

Imai, K., \& Kim, I. S. (2021). On the Use of Two-Way Fixed Effects Regression Models for Causal Inference with Panel Data. Political Analysis, 29(3), 405-415. https://doi.org/10.1017/pan.2020.33

Imbens, G., \& Kalyanaraman, K. (2012). Optimal Bandwidth Choice for the Regression Discontinuity Estimator. The Review of Economic Studies, 79(3), 933-959. https://doi.org/10.1093/restud/ rdr043

Jefferis, E. S., Kaminski, R. J., Holmes, S., \& Hanley, D. E. (1997). The effect of a videotaped arrest on public perceptions of police use of force. Journal of Criminal Justice, 25(5), 381-395. https: //doi.org/10.1016/S0047-2352(97)00022-6

Jeong, J., \& Han, S. (2020). Trust in police as an influencing factor on trust in government: 2SLS analysis using perception of safety. Policing: An International Journal, 43(4), 541-558. https://doi.org/10. 1108/PIJPSM-11-2019-0172

Kääriäinen, J., Isotalus, P., \& Thomassen, G. (2016). Does public criticism Erode trust in the police? The case of Jari Aarnio in the Finnish news media and its effects on the public's attitudes towards the police. Journal of Scandinavian Studies in Criminology and Crime Prevention, 17(1), 70-85. https: //doi.org/10.1080/14043858.2016.1144315

Kang, I. (2021). Beyond Street-LEvel procedural justice: Social construction, policy shift, and ethnic disparities in confidence in government institutions. Governance, gove.12593. https://doi.org/10. 1111 /gove.12593

Kerr, N. L. (1998). HARKing: Hypothesizing After the Results are Known. Personality and Social Psychology Review, 2(3), 196-217. https://doi.org/10.1207/s15327957pspr0203_4

King, G., \& Nielsen, R. (2019). Why Propensity Scores Should Not Be Used for Matching. Political Analysis, 27(4), 435-454. https://doi.org/10.1017/pan.2019.11

Kochel, T. R. (2019). Explaining Racial Differences in Ferguson's Impact on Local Residents' Trust and Perceived Legitimacy: Policy Implications for Police. Criminal Justice Policy Review, 30(3), 374-405. https://doi.org/10.1177/0887403416684923 
A PREPRINT - April 4, 2022

Kochel, T. R., \& Skogan, W. G. (2021). Accountability and transparency as levers to promote public trust and police legitimacy: Findings from a natural experiment. Policing: An International Journal, ahead-of-print. https://doi.org/10.1108/PIJPSM-04-2021-0062

Kritzinger, S., Foucault, M., Lachat, R., Partheymüller, J., Plescia, C., \& Brouard, S. (2021). 'Rally round the flag': The COVID-19 crisis and trust in the national government. West European Politics, 44 (5-6), 1205-1231. https://doi.org/10.1080/01402382.2021.1925017

Labrecque, J., \& Swanson, S. A. (2018). Understanding the Assumptions Underlying Instrumental Variable Analyses: A Brief Review of Falsification Strategies and Related Tools. Current Epidemiology Reports, 5(3), 214-220. https://doi.org/10.1007/s40471-018-0152-1

LaFree, G., \& Adamczyk, A. (2017). The Impact of the Boston Marathon Bombings on Public Willingness to Cooperate with Police. Justice Quarterly, 34(3), 459-490. https://doi.org/10.1080/07418825.2016. 1181780

Lakens, D. (2021). Sample Size Justification (Collabra: Psychology) [Preprint]. PsyArXiv. https://doi. org/10.31234/osf.io/9d3yf

Legewie, J. (2013). Terrorist Events and Attitudes toward Immigrants: A Natural Experiment. American Journal of Sociology, 118(5), 1199-1245. https://doi.org/10.1086/669605

Li, Y., Ren, L., \& Luo, F. (2016). Is bad stronger than good? The impact of police-citizen encounters on public satisfaction with police. Policing: An International Journal of Police Strategies 8 Management, 39(1), 109-126. https://doi.org/10.1108/PIJPSM-05-2015-0058

MacCoun, R. J. (2005). VOICE, CONTROL, AND BELONGING: The Double-Edged Sword of Procedural Fairness. Annual Review of Law and Social Science, 1(1), 171-201. https://doi.org/10.1146/annurev. lawsocsci.1.041604.115958

Mellon, J. (2014). Internet Search Data and Issue Salience: The Properties of Google Trends as a Measure of Issue Salience. Journal of Elections, Public Opinion and Parties, 24(1), 45-72. https://doi.org/10. $1080 / 17457289.2013 .846346$

Muñoz, J., Falcó-Gimeno, A., \& Hernández, E. (2020). Unexpected Event during Survey Design: Promise and Pitfalls for Causal Inference. Political Analysis, 28(2), 186-206. https://doi.org/10.1017/pan. 2019.27

Nägel, C., \& Lutter, M. (2021). The 2017 French riots and trust in the police: A quasi-experimental approach. European Journal of Criminology, 22. https://doi.org/10.1177/1477370821998974

Nagin, D. S., \& Telep, C. W. (2020). Procedural justice and legal compliance: A revisionist perspective. Criminology \& Public Policy, 19(3), 761-786. https://doi.org/10.1111/1745-9133.12499

Nagin, D. S., \& Telep, C. W. (2017). Procedural Justice and Legal Compliance. Annual Review of Law and Social Science, 13, 5-28.

Nussio, E., Bove, V., \& Steele, B. (2019). The consequences of terrorism on migration attitudes across Europe. Political Geography, 75, 102047. https://doi.org/10.1016/j.polgeo.2019.102047

O'Brien, T. C., Meares, T. L., \& Tyler, T. R. (2020). Reconciling Police and Communities with Apologies, Acknowledgements, or Both: A Controlled Experiment. Annals of the American Academy of Political and Social Science, 687, 202-215.

Oglesby-Neal, A., Tiry, E., \& Kim, K. (2019). Public Perceptions of Police on Social Media. Urban Institute, 12.

Page, M. J., McKenzie, J. E., Bossuyt, P. M., Boutron, I., Hoffmann, T. C., Mulrow, C. D., Shamseer, L., Tetzlaff, J. M., Akl, E. A., Brennan, S. E., Chou, R., Glanville, J., Grimshaw, J. M., Hróbjartsson, A., Lalu, M. M., Li, T., Loder, E. W., Mayo-Wilson, E., McDonald, S., .. Moher, D. (2021). The PRISMA 2020 statement: An updated guideline for reporting systematic reviews. BMJ, n71. https: //doi.org/10.1136/bmj.n71 
Perrin, A. J., \& Smolek, S. J. (2009). Who trusts? Race, gender, and the September 11 rally effect among young adults. Social Science Research, 38(1), 134-145. https://doi.org/10.1016/j.ssresearch.2008. 09.001

Perry, G., Jonathan-Zamir, T., \& Weisburd, D. (2017). The Effect of Paramilitary Protest Policing on Protestors' Trust in the Police: The Case of the "Occupy Israel" Movement: Effects of Paramilitary Policing. Law \& Society Review, 51(3), 602-634. https://doi.org/10.1111/lasr.12279

Perugini, M., Gallucci, M., \& Costantini, G. (2018). A Practical Primer To Power Analysis for Simple Experimental Designs. International Review of Social Psychology, 31(1), 20. https://doi.org/10.5334/ irsp.181

Porat, R., Tamir, M., Wohl, M. J. A., Gur, T., \& Halperin, E. (2019). Motivated emotion and the rally around the flag effect: Liberals are motivated to feel collective angst (like conservatives) when faced with existential threat. Cognition and Emotion, 33(3), 480-491. https://doi.org/10.1080/02699931.2018.1460321

Reny, T. T., \& Newman, B. J. (2021). The Opinion-Mobilizing Effect of Social Protest against Police Violence: Evidence from the 2020 George Floyd Protests. American Political Science Review, 1-9. https://doi.org/10.1017/S0003055421000460

Revkin, M. (2022). How does subnational variation in repression affect attitudes toward police? Evidence from Iraq's 2019 protests. Violence: An International Journal.

Roché, S., \& Roux, G. (2017). The "silver bullet" to good policing: A mirage: An analysis of the effects of political ideology and ethnic identity on procedural justice. Policing: An International Journal, 40(3), 514-528. https://doi.org/10.1108/PIJPSM-05-2016-0073

Rosenthal, N. E., \& Wehr, T. A. (1987). Seasonal Affective Disorders. Psychiatric Annals, 17(10), 670-674. https://doi.org/10.3928/0048-5713-19871001-10

Rozin, P., \& Royzman, E. B. (2001). Negativity Bias, Negativity Dominance, and Contagion. Personality and Social Psychology Review, 5(4), 296-320. https://doi.org/10.1207/S15327957PSPR0504_2

Sampson, R. J. (2010). Gold Standard Myths: Observations on the Experimental Turn in Quantitative Criminology. Journal of Quantitative Criminology, 26(4), 489-500. https://doi.org/10.1007/ s10940-010-9117-3

Sangnier, M., \& Zylberberg, Y. (2017). Protests and trust in the state: Evidence from African countries. Journal of Public Economics, 152, 55-67. https://doi.org/10.1016/j.jpubeco.2017.05.005

Schraff, D. (2020). Political trust during the Covid-19 pandemic: Rally around the flag or lockdown effects? European Journal of Political Research, 1475-6765.12425. https://doi.org/10.1111/1475-6765.12425

Sibley, C. G., Greaves, L. M., Satherley, N., Wilson, M. S., Overall, N. C., Lee, C. H. J., Milojev, P., Bulbulia, J., Osborne, D., Milfont, T. L., Houkamau, C. A., Duck, I. M., Vickers-Jones, R., \& Barlow, F. K. (2020). Effects of the COVID-19 pandemic and nationwide lockdown on trust, attitudes toward government, and well-being. American Psychologist, 75(5), 618-630. https://doi.org/10.1037/amp0000662

Skogan, W. G. (2006). Asymmetry in the Impact of Encounters with Police. Policing and Society, 16(2), 99-126. https://doi.org/10.1080/10439460600662098

Skovron, C., \& Titiunik, R. (2015). A Practical Guide to Regression Discontinuity Designs in Political Science. Preprint, 1-36.

Stock, J. H., \& Watson, M. W. (2007). Introduction to econometrics (2. ed., Pearson international ed). Pearson Addison-Wesley.

Stoll, C. R. T., Izadi, S., Fowler, S., Green, P., Suls, J., \& Colditz, G. A. (2019). The value of a second reviewer for study selection in systematic reviews. Research Synthesis Methods, 10(4), 539-545. https: //doi.org/10.1002/jrsm.1369

Stommes, D., Aronow, P. M., \& Sävje, F. (2021). On the reliability of published findings using the regression discontinuity design in political science. http://arxiv.org/abs/2109.14526 
Sunshine, J., \& Tyler, T. R. (2003). The Role of Procedural Justice and Legitimacy in Shaping Public Support for Policing. Law<Html_ent Glyph="@amp;" Ascii="Éamp;"/> Society Review, 37(3), 513-548. https://doi.org/10.1111/1540-5893.3703002

Thomassen, G., Strype, J., \& Egge, M. (2014). Trust no Matter What? Citizens' Perception of the Police 1 Year after the Terror Attacks in Norway. Policing, 8(1), 79-87. https://doi.org/10.1093/police/pat032

Turchan, B. (2021). A high-profile police-involved shooting, civil unrest, and officers' perceptions of legitimacy: Insights from a natural experiment. Journal of Experimental Criminology, 17(3), 507-518. https: //doi.org/10.1007/s11292-020-09413-2

Tyler, T. R. (2006). Why People Obey the Law. Princeton University Press.

Tyler, T. R., \& Huo, Y. J. (2002). Trust in the Law: Encouraging Public Cooperation with the Police and Courts. Russell Sage Foundation.

Tyler, T. R., \& Jackson, J. (2014). Popular legitimacy and the exercise of legal authority: Motivating compliance, cooperation, and engagement. Psychology, Public Policy, and Law, 20(1), 78-95.

Van Hauwaert, S. M., \& Huber, R. A. (2020). In-group solidarity or out-group hostility in response to terrorism in France? Evidence from a regression discontinuity design. European Journal of Political Research, 59(4), 936-953. https://doi.org/10.1111/1475-6765.12380

Vidales, G., Day, K. M., \& Powe, M. (2009). Police and immigration enforcement: Impacts on Latino(a) residents' perceptions of police. Policing: An International Journal of Police Strategies 85 Management, 32(4), 631-653. https://doi.org/10.1108/13639510911000740

Waffenschmidt, S., Knelangen, M., Sieben, W., Bühn, S., \& Pieper, D. (2019). Single screening versus conventional double screening for study selection in systematic reviews: A methodological systematic review. BMC Medical Research Methodology, 19(1), 132. https://doi.org/10.1186/s12874-019-0782-0

Walters, G. D., \& Bolger, P. C. (2019). Procedural justice perceptions, legitimacy beliefs, and compliance with the law: A meta-analysis. Journal of Experimental Criminology, 15(3), 341-372. https://doi.org/ $10.1007 / \mathrm{s} 11292-018-9338-2$

Weitzer, R. (2002). Incidents of police misconduct and public opinion. Journal of Criminal Justice, 30(5), 397-408. https://doi.org/10.1016/S0047-2352(02)00150-2

Weitzer, R. (2019). Recent trends in police-citizen relations and police reform in the United States. In D. Oberwittler \& S. Roché, Police-Citizen Relations Across the World: Comparing sources and contexts of trust and legitimacy (pp. 29-45). Routledge.

White, C., Weisburd, D., \& Wire, S. (2018). Examining the Impact of the Freddie Gray Unrest on Perceptions of the Police: Freddie Gray Unrest. Criminology \& Public Policy, 17(4), 829-858. https: //doi.org/10.1111/1745-9133.12404

Zoorob, M. (2020). Police Legitimacy and Citizen Coproduction: How does publicized police brutality impact calling the police? [Preprint]. Politics and International Relations. https://doi.org/10.33774/ apsa-2020-57r7f 